\title{
Severely Uncontrolled Diabetes in the Over-Fifties
}

\author{
E. A. M. Gale, T. L. Dornan and R. B. Tattersall \\ Diabetic Department, Nottingham University Hospital, Nottingham, UK
}

Summary. Between 1969 and 1976, 317 adults were admitted to hospital in Nottingham with severely uncontrolled diabetes (plasma glucose over $33 \mathrm{mmol} / 1$ and/or venous bicarbonate less than $14 \mathrm{mmol} / \mathrm{l})$. A third of episodes were in patients over the age of 50 years, of which $43 \%$ were fatal. In contrast, only $3.4 \%$ of episodes in patients under 50 years were fatal. In the older group, $65 \%$ of deaths occurred within $48 \mathrm{~h}$ of admission and in $44 \%$ no cause was found other than uncontrolled diabetes. Later deaths were due to underlying disease, infection or thromboembolism. Amongst older patients $38 \%$ were not previously known to have diabetes. Presentation to hospital was late and we conclude that many deaths were potentially avoidable by earlier detection in the community.

Key words: Elderly diabetics, diabetic coma, ketoacidosis, hyperosmolar coma, hypothermia

Age is one of the most important prognostic factors in severely uncontrolled diabetes. Before 1940 mortality in patients over the age of 50 years was over $50 \%[1,2]$. Results have improved but mortality in elderly patients may still be over $20 \%$ [3-6] (Table 1). There have only been two studies devoted specifically to elderly patients with severely uncontrolled diabetes $[7,8]$ and in these $12 \%$ and $22 \%$ respectively of patients over the age of 60 years died. One aspect of uncontrolled diabetes in the elderly which has been intensively studied is the non-ketotic hyperosmolar state; this usually presents in older patients and is fatal in 30-50\% [9].

When analysing admissions with severely uncontrolled diabetes in our area, we found an unexpectantly high proportion of older patients. We present this large, unselected, retrospective series, to draw attention to the special problems and characteristics of uncontrolled diabetes in the elderly.

\section{Patients and Methods}

Nottingham is an industrial city in the English Midlands with a catchment area of 600,000. All emergencies are seen in one casualty department and go to only two general hospitals. We used the computer-assisted Hospital Activities Analysis Index to identify all admissions with severely uncontrolled diabetes between 1969 and 1976 inclusive. Rather than relying on key words such as 'diabetic coma', we ascertained our cases by looking through the records of all admissions listed as having diabetes, whatever the final diagnosis. Paediatric admissions were excluded.

Most patients were admitted as emergencies under the 'onduty' medical team and were not treated on the intensive care unit except where there were special indications (e.g. a need for assisted ventilation). There is no acute geriatric unit and all acutely ill medical patients, irrespective of age, went to general physicians. This series is therefore unselected and representative of the spectrum of uncontrolled diabetes in a community. For the sake of completeness, we also checked the coroner's records for deaths outside hospital attributed to uncontrolled diabetes.

\section{Criteria}

Patients were included if they had a blood glucose level $\$ 33 \mathrm{mmol} / 1(600 \mathrm{mg} / 100 \mathrm{ml})$ or a venous bicarbonate $₹ 14 \mathrm{mmol} / \mathrm{l}$ with plasma ketones on testing with Acetest or Ketostix (Ames) or heavy ketonuria. These criteria were applied regardless of underlying or associated disease. Death was defined as 'failure to leave hospital alive' and patients were not excluded, as in some series, because they were moribund on arrival or had associated illness which in itself might be expected to cause death. Patients with phenformin-induced lactic acidosis over the same period have been previously reported [10] and are not included here.

\section{Results}

Over the seven year period, 259 patients had 317 episodes of uncontrolled diabetes as defined above. Thirty-five percent occurred in 106 patients over the age of 50 years; of these, $43 \%$ were fatal (Table 2 ). The older group included three West Indian women, but all other patients were of European origin. Below the age of 50 years, 153 patients had 205 episodes of which $3.4 \%$ were fatal. Recurrent episodes of uncon- 
Table 1. Mortality in previous reports of diabetic "Coma"

\begin{tabular}{|c|c|c|c|c|c|}
\hline $\begin{array}{l}\text { Reference } \\
\text { (first author/year) }\end{array}$ & $\begin{array}{l}\text { No. } \\
\text { episodes }\end{array}$ & $\begin{array}{l}\text { Patients } \\
\text { under } \\
50 \text { years } \\
(\%)\end{array}$ & $\begin{array}{l}\text { Deaths } \\
(\%)\end{array}$ & $\begin{array}{l}\text { Patients } \\
\text { over } \\
50 \text { years } \\
(\%)\end{array}$ & $\begin{array}{l}\text { Deaths } \\
(\%)\end{array}$ \\
\hline Joslin (1937) [12] & 318 & 83 & 6.8 & 17 & 37.7 \\
\hline Rabinowitch (1939) [13] & 819 & 77 & 16.1 & 22 & 60.0 \\
\hline Beardwood (1941) [14] & 220 & 76 & 14.1 & 24 & 39.6 \\
\hline Collen (1942) [2] & 315 & 75 & 25.8 & 25 & 55.7 \\
\hline Harwood (1951) [15] & 67 & 75 & 0 & 25 & 5.9 \\
\hline Greenaway (1958) [3] & 69 & 70 & 2.1 & 30 & 47.6 \\
\hline Cohen (1960) [4] & 73 & 78 & 0 & 22 & 25.0 \\
\hline Fitzgerald (1961) [16] & 160 & 65 & 6.7 & 35 & 21.4 \\
\hline Beigelman (1971) [6] & 482 & 86 & 2.9 & 14 & 29.0 \\
\hline This study (1980) & 317 & 65 & 3.4 & 35 & 43.0 \\
\hline \multicolumn{6}{|c|}{ Mortality over the age of 60 years } \\
\hline & & $\begin{array}{l}\text { Under } \\
60 \text { years }\end{array}$ & & $\begin{array}{l}\text { Over } \\
60 \text { years }\end{array}$ & \\
\hline Barnett (1961) [7] & 401 & 83 & 5.0 & 13 & 11.8 \\
\hline Campbell (1973) [8] & 211 & 87 & $?$ & 13 & 22.2 \\
\hline This study (1980) & 317 & 74 & 6.8 & 26 & 47.0 \\
\hline
\end{tabular}

trolled diabetes caused no deaths below the age of 40 years but in contrast, two of six patients in the fifth decade and three of six over 50 years died in their second or subsequent episode.

A search through the coroner's records showed that one 65-year-old woman, previously undiagnosed, died at home in ketoacidosis.

\section{Patients Over 50 Years Old}

History Before Admission: Thirty-eight percent of episodes in older patients were in previously undiagnosed diabetics, compared with $20 \%$ in the younger group (Table 2). Illness often developed insidiously over several weeks or even months in older patients, followed by a sharp deterioration. Forty-one patients $(37 \%)$ are known to have consulted a doctor in the two weeks before admission. The proportion may have been higher but could not be determined retrospectively from the notes. There were 70 episodes in known diabetics, of whom $54 \%$ were on insulin, $32 \%$ on tablets and $14 \%$ on diet alone. The insulin-treated patients had a mean diabetes duration of 17 years (range 6 months to 48 years); mean duration of tablet treatment was seven years. Of known diabetics, $49 \%$ were attending a clinic.

Precipitating Factors: The single most important precipitating factor was diabetes of recent onset (42 of 112 episodes). Next came social isolation - 32 patients lived alone. No fewer than nine were admitted after being found lying on the floor by the police when called in by neighbours. Other factors, sometimes multiple, included stopping insulin (four patients) or tablets (two), myocardial infarction (two), heart failure (two), pneumonia (three), pancreatitis, fractured femur, cellulitis of a foot, skin abscess and treatment with steroids or diazoxide (one each). There was no apparent precipitating cause in $41(37 \%)$. Two patients developed severely uncontrolled diabetes in hospital, one after haemorrhagic pancreatitis and one after a heart attack.

Clinical Features on Admission: On arrival at hospital, $21 \%$ of patients were conscious and alert (grade 1), $39 \%$ were drowsy but able to talk (grade 2), $21 \%$ were comatose but responded to painful stimuli (grade 3) and 20\% were deeply unconscious (grade 4). Twenty-two percent of patients in grade $1,34 \%$ in grade $2,43 \%$ in grade 3 , and $82 \%$ in grade 4 , died. Nine patients presented with severe hypothermia (rectal temperature below $33{ }^{\circ} \mathrm{C}$ ) of whom six died [11]. Thirty-four percent had a systolic blood pressure of $100 \mathrm{mmHg}$ or below, of whom $61 \%$ died; 15 of these deaths occurred in 19 patients with a systolic pressure of $80 \mathrm{mmHg}$ or less. Abdominal pain or tenderness was noted in nine patients who later had no clinical or post mortem evidence of intra-abdominal disease.

Biochemical Features: Adequate biochemical data were available for 110 episodes; records were incomplete for two patients, one of whom died within minutes of admission. The biochemical and clinical findings in relation to plasma bicarbonate levels are 
shown in Table 3. Seventy-six percent had a bicarbonate level of $15 \mathrm{mmol} / \mathrm{l}$ or below and $24 \%$ a level between 15 and $30 \mathrm{mmol} / \mathrm{l}$. Sixty-five percent of 'hyperosmolar' patients were previously undiagnosed diabetics, compared with $31 \%$ in the 'ketoacidotic' group. Grade 3 or 4 coma, hypothermia and hypotension were more common in the 'ketoacidotic' group but the death rate in the 'hyperosmolar' group was higher (58 against $38 \%$ ). The time of death in the two groups differed; $78 \%$ of ketoacidotic deaths were within $48 \mathrm{~h}$ of admission and $56 \%$ were classed as 'metabolic' (see below). In contrast, only six of 15 deaths $(40 \%)$ in the 'hyperosmolar' group occurred in the first $48 \mathrm{~h}$ and only three were 'metabolic'.

Outcome: Sixty-five percent of deaths occurred within $48 \mathrm{~h}, 15 \%$ between 2 and 7 days and $20 \%$ thereafter. Autopsies were performed in 30 of the 48 deaths. Uncontrolled diabetes alone appeared to have caused 21 of the 31 deaths in the first $48 \mathrm{~h}$ after admission; the other 10 had serious underlying illness such as pyelonephritis, myocardial infarction, pancreatitis, mesenteric infarction, meningitis, renal failure and acute bacterial endocarditis. Of the 17 deaths after the first $48 \mathrm{~h}$, five were due to pulmonary embolism, five to bronchopneumonia and four to arterial occlusion.

Factors Influencing Mortality: As in almost all other series (Table 1) age was the most important determinant of mortality. When death occurred within the first $48 \mathrm{~h}, 15$ of 21 patients had three or more of the following adverse features; grade 3 or 4 coma, systolic blood pressure below $100 \mathrm{mmHg}$, rectal temperature below $33^{\circ} \mathrm{C}$, blood glucose over $60 \mathrm{mmol} / \mathrm{l}$ or blood urea over $30 \mathrm{mmol} / \mathrm{l}$. The only two 'metabolic' deaths without any of these adverse features were in patients over 80 years old. As expected, unconsciousness had a poor prognosis; $82 \%$ of patients in deep coma died as against $22 \%$ of those who were fully conscious on admission.

Associated severe disease led to 10 of 31 deaths in the first $48 \mathrm{~h}$. Surprisingly, there was only one case of myocardial infarction.

Previously unrecognised diabetes had an unfavourable prognosis, whereas those already on insulin did relatively well. Of 42 patients not previously known to have diabetes, $50 \%$ died whereas only $30 \%$ of 37 patients already on insulin died.

Different forms of treatment did not appear to affect the prognosis. Intermittent low-dose insulin was introduced during the period of study and was used in 30 patients, $43 \%$ of whom died. The use of bicarbonate ( 34 patients) did not influence mortality. No deaths were caused by fluid overload or hypokalaemia.
Table 2. Summary of 317 episodes of severely uncontrolled diabetes in Nottingham 1969-1976

\begin{tabular}{ll}
\hline Under 50 years & Over 50 years \\
\hline Patients: 153 & Patients: 106 \\
male: 71 , female: 82 & male: 27, female: 79 \\
Previously undiagnosed & Previously undiagnosed \\
$\quad$ diabetes $20 \%$ & diabetes $38 \%$ \\
Episodes: 205 & Episodes: 112 \\
Fatal episodes: $3.4 \%$ & Fatal episodes: $43 \%$ \\
\hline
\end{tabular}

Table 3. Venous bicarbonate levels related to other clinical and biochemical features in 110 patients over 50 years old with severely uncontrolled diabetes

\begin{tabular}{|c|c|c|}
\hline & \multicolumn{2}{|c|}{ Venous bicarbonate $(\mathrm{mmol} / \mathrm{l})$} \\
\hline & 15 or below & $16-30$ \\
\hline No. patients & 84 & 26 \\
\hline Previously undiagnosed & $31 \%$ & $65 \%$ \\
\hline Systolic BP below $100 \mathrm{mmHg}$ & $38 \%$ & $27 \%$ \\
\hline Grade $3+4$ coma & $45 \%$ & $27 \%$ \\
\hline Rectal temperature below $35^{\circ} \mathrm{C}$ & $21 \%$ & $8 \%$ \\
\hline Mean blood glucose $(\mathrm{mmol} / \mathrm{l})$ & 48.3 & 53.5 \\
\hline Mean osmolality (mosm $/ \mathrm{kg}$ ) & 354 & 374 \\
\hline Mean blood urea $(\mathrm{mmol} / \mathrm{l})$ & 20.4 & 24.7 \\
\hline Death & $32(38 \%)$ & $15(58 \%)$ \\
\hline "Metabolic death" & $18(21 \%)$ & $3(11 \%)$ \\
\hline
\end{tabular}

\section{Discussion}

The high mortality of uncontrolled diabetes in older patients is the most striking feature of this study and is consistent with most other reports $[2-4,6,12-16]$. The only two previous reports dealing specifically with older patients $[7,8]$ were from specialist units and reported mortalities of 12 and $22 \%$, respectively. It is difficult to compare the outcome of treatment of uncontrolled diabetes in different centres since results will be affected by the type of patient referred, which depends on population structure, standards of primary health care and patterns of referral. Our patients were not treated on an intensive care unit and the high mortality could be due to bad management, although this seems unlikely because mortality under the age of 50 years was $3.4 \%$ which is similar to that in other centres. A more probable reason for the high mortality is that this series is an unselected one from a total community and hence includes patients who would not have been referred to a specialist unit either because they were considered too old or because the referring doctor did not realise that their illness was due to diabetes. In the only other total community study in Rochester, Min- 
nesota, results were similar to ours; the incidence of severely uncontrolled diabetes in patients diagnosed over the age of 30 years was 3.3/thousand/year and the mortality in this group $34 \%$, of whom more than one-third died in the first $24 \mathrm{~h} \mathrm{[17].}$

One reason for the high mortality in elderly patients is the presence of associated disease which accounted for $56 \%$ of deaths in our series. However, $44 \%$ died early metabolic deaths and many were so ill when they reached hospital that the fatal outcome was a foregone conclusion. Yet, one-third had consulted a doctor in the two weeks before admission. Why was diagnosis so poor? One reason might be that symptoms are less obviously 'diabetic' in the elderly; thirst is less prominent, acidotic breathing may be mis-diagnosed as heart failure or pneumonia, urinary frequency as infection or prostatism and mental confusion as cerebrovascular disease. The absence of acidotic breathing, vomiting or ketonuria may lead the practitioner to underestimate the severity of the metabolic disturbance. In this context, it is interesting that patients already on insulin have a lower mortality, possibly because this treatment suggested 'severe' diabetes and prompted earlier referral. Failure of diagnosis is not confined to older patients; in one study [18], 12 of 15 new diabetics presenting in ketoacidosis had visited a doctor on 41 occasions and in 22 no urine test was done.

Zieve and Hill $[19,20]$ analysed prognostic factors in severely uncontrolled diabetes and found age to be the most important, although it had 'no independent contribution'. In other words, older patients died because they were iller both biochemically and clinically, as others have reported $[6,7]$. This was also true in our study. It has been suggested that hyperosmolar coma has a higher mortality than ketoacidosis $[9,21,22]$. We found a high mortality in both conditions in the elderly. The main difference was that more patients with ketoacidosis died 'early metabolic' deaths, whereas patients with hyperosmolar coma tended do die later from thromboembolism. Diabetic metabolic emergencies are often avoidable and more attention should be directed to cause and prevention rather than cure. We hope that this report will draw attention to some of the special problems of diabetes in the elderly.

Acknowledgements. We thank Rachel Worley, Jane Richards, Leora Hoffman and Pamela Sutton for typing our manuscript and Mr. Ray Nutt and the staff of the Medical Records Department in the North and South Nottingham Districts for their help in tracing many hundreds of records. We are grateful to out colleagues for allowing us access to the records of patients admitted under their care and to Dr. H. M. Rice who allowed us to look at records of coroner's post-mortems in Nottingham.

\section{References}

1. Dillon ES, Dyer WW (1937) Factors influencing the prognosis in diabetic coma. Ann Intern Med 11: 602-617

2. Collen MF (1942) Mortality in diabetic coma. Arch Intern Med 70: 347-368

3. Greenaway JM, Read J (1958) Diabetic coma: A review of 69 cases. Aust Ann Med 7: 151-159

4. Cohen AS, Vance VK, Runyan JW, Hurwitz D (1960) Diabetic acidosis: An evaluation of the cause, course and therapy of 73 cases. Ann Intern Med 52: 55-86

5. Soler NG, Bennett MA, Fitzgerald MG, Malins JM (1973) Intensive care in the management of diabetic ketoacidosis. Lancet 1: 951-954

6. Beigelman PM (1971) Severe diabetic ketoacidosis (diabetic "coma") 482 episodes in 257 patients; experience of three years. Diabetes 20: 490-500.

7. Barnett DM, Wilcox DS, Marble A (1961) Diabetic coma in persons over 60. Geriatrics 17: 327-336

8. Campbell IW, Munro JF, Duncan LJP (1973) Severe diabetic metabolic decompensation in the elderly. Age and Ageing 2: 199-206

9. McCurdy DK (1970) Hyperosmolar hyperglycaemic nonketotic diabetic coma. Med Clin North Am 54: 683-699

10. Gale EAM, Tattersall RB (1976) Can phenformin-induced lactic acidosis be prevented? Br Med J 2: 972-975

11. Gale EAM, Tattersall RB (1978) Hypothermia, a complication of diabetic ketoacidosis. Br Med J 2: 1387-1389

12. Joslin EP, Root HF, White P, Marble A, Joslin AP (1937) Diabetic coma. An investigation of mortality and report of a severity index for comparative studies. Ann Intern Med 12: 1403-1428

13. Rabinowitch IM, Fowler AF, Bensley EH (1939) Diabetic coma, An investigation of mortality and report of a severity index for comparative studies. Ann Intern Med 12: 1403-1428

14. Beardwood JT, Rouse GP (1941) Diabetic acidosis. A study of two hundred and twenty consecutive cases. J Am Med Assoc; $1701-1704$

15. Harwood R (1951) Diabetic acidosis: Results of treatment in 67 consecutive cases. N Engl J Med 245: 1-9

16. Fitzgerald MG, O'Sullivan DJ, Malins JM (1961) Fatal diabetic ketosis. Br Med J 1: 247-250

17. Johnson DD, Palumbo PJ, Chu-Pin Chu (1980) Diabetic ketoacidosis in a community based population. Mayo Clin Proc 55: 83-88

18. Pyke DA (1980) Editorial. "Mistakes in Medicine". J R Coll Physicians London 14: 68

19. Zieve L, Hill E (1953) Descriptive characteristics of group of patients with moderate or severe diabetic acidosis: relation to recovery or death. Arch Intern Med 92: 51-62

20. Zieve L, Hill E (1953) Prognosis in moderate or severe diabetic acidosis. Arch Intern Med 92: 63-74

21. Alberti KGMM, Hockaday TDR (1977) Diabetic coma: A reappraisal after 5 years. Clin Endocrinol Metab 6: 421-455

22. Clements RS, Vourganti B (1978) Fatal diabetic ketoacidosis: major causes and approaches to their prevention. Diabetes Care 1: 314-325

Received: 1 December 1980

and in revised form: 2 February 1981

Dr. R. B. Tattersall

Diabetic Department

University Hospital

Queen's Medical Centre

Nottingham NG7 2UH, UK 